\title{
Article \\ The Effect of Hot Water Extract of Tilapia on Exercise Capacity in Mice
}

\author{
Hui-Yun Tsai ${ }^{1,2}$, Jia-Fang Yang ${ }^{3}$, Hua-Han Chen ${ }^{4}$, Fu-Nian You ${ }^{3}$, Yu-Jie Zhao ${ }^{3}$, Yi-Hsien Lin ${ }^{5}$ (D), \\ Jue-Liang Hsu ${ }^{6} \mathbb{D}$, Chi-I Chang ${ }^{6}$ and Yu-Kuo Chen ${ }^{3, * \mathbb{D}}$
}

check for updates

Citation: Tsai, H.-Y.; Yang, J.-F.; Chen, H.-H.; You, F.-N.; Zhao, Y.-J.; Lin, Y.-H.; Hsu, J.-L.; Chang, C.-I.; Chen, Y.-K. The Effect of Hot Water Extract of Tilapia on Exercise Capacity in Mice. Appl. Sci. 2022, 12, 2601. https://doi.org/10.3390/app12052601

Academic Editors: Jesus Simal-Gandara, Jianbo Xiao and Md Afjalus Siraj

Received: 30 January 2022 Accepted: 28 February 2022

Published: 2 March 2022

Publisher's Note: MDPI stays neutral with regard to jurisdictional claims in published maps and institutional affiliations.

Copyright: (c) 2022 by the authors. Licensee MDPI, Basel, Switzerland. This article is an open access article distributed under the terms and conditions of the Creative Commons Attribution (CC BY) license (https:/ / creativecommons.org/licenses/by/ $4.0 /)$.
1 Department of Nutrition and Health Science, Fooyin University, Kaohsiung 83102, Taiwan; rhytsai@gmail.com 2 Aging and Disease Prevention Research Center, Fooyin University, Kaohsiung 83102, Taiwan

3 Department of Food Science, National Pingtung University of Science and Technology, Pingtung 91201, Taiwan; jane115489@gmail.com (J.-F.Y.); roxer697@gmail.com (F.-N.Y.); a0913026689@gmail.com (Y.-J.Z.)

4 Department of Food Science, National Penghu University of Science and Technology, Penghu 88046, Taiwan; huahan@gms.npu.edu.tw

5 Department of Plant Medicine, National Pingtung University of Science and Technology, Pingtung 91201, Taiwan; yhlin@mail.npust.edu.tw

6 Department of Biological Science and Technology, National Pingtung University of Science and Technology, Pingtung 91201, Taiwan; jlhsu@mail.npust.edu.tw (J.-L.H.); changchii@mail.npust.edu.tw (C.-I.C.)

* Correspondence: chenyk@mail.npust.edu.tw; Tel.: +886-8-7703202 (ext. 7044); Fax: +886-8-7740378

\begin{abstract}
Tilapia (Oreochromis mossambicus) has become one of the main aquatic products of Taiwan. The aim of this study was to evaluate the efficacy of a hot water extract of tilapia (HWET) in relieving fatigue and enhancing exercise performance in mice in a swimming endurance test. Male ICR mice were randomly divided into four groups ( $\mathrm{n}=10$ per group) and treated with either a vehicle (control group) or different doses of HWET, which were designated as HWET-L ( $800 \mathrm{mg} / \mathrm{kg} /$ day), HWET-M $(1600 \mathrm{mg} / \mathrm{kg} /$ day), and HWET-H (4000 mg/kg/day). The results of the swimming endurance test showed that HWET treatment significantly improved exercise-induced fatigue as the swimming time of the mice increased $(p<0.05)$. One hour after the test, blood samples were collected from each mouse and serum biochemical parameters were measured. The serum levels of lactate, creatine kinase $(\mathrm{CK})$, and blood urea nitrogen (BUN) were lower in mice treated with HWET compared to the control group. Moreover, HWET treatment increased serum glucose levels and glycogen content in the liver. Enhanced glutathione (GSH) content in the liver and muscle was also found in the HWET-M and HWET-H groups. Western blot results showed that the expression of tumor necrosis factor- $\alpha$ (TNF- $\alpha)$ in the liver tissue was downregulated by HWET treatment. Taken together, our results demonstrate that HWET supplementation could enhance exercise performance and alleviate fatigue via biochemical profile improvements. This suggests that HWET has the potential for future development into functional foods or nutritional supplements to relieve fatigue.
\end{abstract}

Keywords: tilapia (Oreochromis mossambicus); anti-fatigue; exercise capacity; glycogen; glutathione

\section{Introduction}

Fatigue, a common term describing a gradual decline in energy and activity, is a highly exhausted feeling that can lead to a variety of physical and emotional discomforts, such as reduced concentration, slowed reflexes and responses, or feeling abnormally sleepy [1,2]. Fatigue has become an important global issue since it affects approximately $20 \%$ of the population in several developed countries [3]. Forms of physical fatigue can be classified as either central or peripheral [4,5]. The former occurs in the central nervous system, and relates to key components in muscle that increase during exercise, such as hydrogen ions, potassium ions, phosphates, prostaglandins, etc. These components bind to specific fatigue receptors in the muscle, then transmit signals to the brain through the sensory nerves [6]. The decline in blood glucose levels with central fatigue limits the glucose 
utilization of neurons in the brain, and changes in plasma amino acid concentration have also been identified [7]. Peripheral fatigue is mainly caused by the depletion of energy stores (e.g., glycogen or phosphocreatine in the liver and muscles) and the accumulation of excess metabolites during physical activity (e.g., lactate in muscle) [8]. All phenomena of central and peripheral fatigue, as described above, are suitable biochemical indicators for assessing the degree of fatigue. The formation of oxidative stress in active skeletal muscle and the liver is also involved in exercise-induced fatigue [9]. Oxidative stress activates the inflammatory response via enhanced expression of pro-inflammatory cytokines like tumor necrosis factor$\alpha(\mathrm{TNF}-\alpha)[10]$ and causes the depletion of the antioxidant glutathione (GSH) [11].

Nowadays, fatigue is a common issue for most people, and it results in negative effects such as inattention and mental paralysis at work, which leads to a decline in efficiency. Moreover, fatigue is a health-related state that is highly correlated with a lower quality of life, and which can cause fatigue syndrome and even physical and emotional discomfort [12]. Therefore, the search for natural food sources to develop functional supplements that improve athletic capacity and boost fatigue recovery has become the focus of research [13]. Reports have shown that several active components in nature possess an anti-fatigue activity, such as proanthocyanidin [14], flavonoids [15], terpenoids [16], nucleotides [17], peptides [18], polysaccharides [19], and amino acids [7,20]. Recently, extracts and components from aquatic products, such as leather carp (Cyprinus carpio) and grass carp (Ctenopharyngodon idellus), have been shown to enhance the exercise performance of mice during swimming endurance tests [21,22].

Tilapia (Oreochromis mossambicus), a tropical fish species of Cichlidae originating in Africa, is now the third most globally farmed fish, after carp and salmon, with a worldwide production of 4,800,000 tons in 2013 [23]. Tilapia was first introduced to Taiwan in 1944, and then improved through breeding before being renamed Wu-Kuo Yu (fish) in Chinese, also known as Taiwanese tilapia [24]. Tilapia has become one of the major freshwater aquaculture species in Taiwan due to its rapid growth, stable price, and the availability of mature processing technology. Furthermore, because of its high protein and mineral levels and relatively low fat content, tilapia is an aquatic product with high nutritional value. In the present study, we further investigate the effects of a hot water extract of tilapia (HWET) on exercise-induced fatigue in mice using a swimming endurance test.

\section{Materials and Methods}

\subsection{Material Preparation and Analysis}

Hot water extract of tilapia (HWET) was obtained from Li Chuan Aquafarm Co., Ltd. (Hualien, Taiwan). Briefly, fresh tilapia were sliced into fillets and extracted using boiling water at a 1:20 (kg/L) ratio for $24 \mathrm{~h}$. After centrifugation to remove the oil layer and residue, the extract was lyophilized and powdered, before being resuspended in distilled water to obtain the required dosage. The HWET contains about $91.7 \%$ protein, $6.9 \%$ fat and trace amounts of sodium and cholesterol. The taurine and hydrolyzed amino acid profiles of HWET were analyzed by Tentamus Analytics Taiwan Co., Ltd. (Kaohsiung, Taiwan) and are shown in Table 1.

\subsection{Animals and Treatment}

Male ICR mice aged 6 to 7 weeks (27-30 g) were purchased from BioLASCO Taiwan Co., Ltd. (Yi-Lan, Taiwan). The mice were housed at the National Pingtung University of Science and Technology (Pingtung, Taiwan). All animal experiments were carried out according to protocol NPUST-110-038, approved by the Institutional Animal Care and Use Committee of National Pingtung University of Science and Technology. The mice were fed with standard Purina chow (\#5001, Purina, St. Louis, MO, USA) ad libitum, and their food intake was recorded daily. Mouse body weight was monitored weekly throughout the course of the experiment.

Following an adaptation period of one week, the mice were randomly divided into four groups ( $\mathrm{n}=10$ per group): the control group (vehicle), and three HWET treatment 
groups, which were designated as low dosage (HWET-L, $800 \mathrm{mg} / \mathrm{kg} /$ day), medium dosage (HWET-M, 1600 mg/kg/day), and high dosage (HWET-H, $4000 \mathrm{mg} / \mathrm{kg} /$ day). Vehicle and HWET were administrated by oral gavage for 7 days.

Table 1. Taurine and hydrolyzed amino acid profiles of hot water extract of tilapia (HWET).

\begin{tabular}{lc}
\hline Amino Acids & Content $\mathbf{( m g / g )}$ \\
\hline Taurine & 14.7 \\
Aspartic acid & 56.9 \\
Glutamic acid & 102.3 \\
Serine & 30.0 \\
Histidine & 9.5 \\
Glycine & 165.3 \\
Threonine & 25.0 \\
Arginine & 56.9 \\
Alanine & 91.9 \\
Tyrosine & 6.9 \\
Cystine & 14.2 \\
Valine & 16.3 \\
Methionine & 9.0 \\
Phenylalanine & 21.7 \\
Isoleucine & 10.8 \\
Leucine & 30.0 \\
Lysine & 30.4 \\
Proline & 70.9 \\
\hline
\end{tabular}

Taurine and hydrolyzed amino acid profiles were provided by Tentamus Analytics Taiwan Co., Ltd.

\subsection{Swimming Endurance Test}

To evaluate the effect of HWET on exercise performance, a two-day pre-swim test referenced and modified from Lee et al. [22] was conducted before the start of the experiment to allow the mice to adapt to endurance swimming. In brief, $30 \mathrm{~min}$ following treatment on days 0 and 3, the mice were individually placed in a plastic container $(20.5 \mathrm{~cm}$ height, $24 \mathrm{~cm}$ in diameter) filled with water $\left(27 \pm 1^{\circ} \mathrm{C}\right)$ at a depth of $11-13 \mathrm{~cm}$ for training. On the 7 th day of the experiment, $1 \mathrm{~h}$ after oral administration of the sample, the mice were placed in the plastic container for a 10 min swimming endurance test. The total duration of immobility was recorded, including the time when struggling ceased and the mouse remained motionless in the water. Total swimming time was calculated by subtracting the period of immobility.

\subsection{Blood Collection and Tissue Harvesting}

One hour after the swimming endurance test, the mice were euthanized. Blood was collected and serum samples were prepared and stored at $-80^{\circ} \mathrm{C}$ until analysis. Liver and muscle forelimb tissues were harvested and weighed before the tissues were frozen in liquid nitrogen and stored at $-80^{\circ} \mathrm{C}$ for subsequent glycogen and glutathione (GSH) measurements, as well as determination of tumor necrosis factor- $\alpha$ (TNF- $\alpha$ ) expression.

\subsection{Biochemical Analyses of Serum}

Serum lactate levels were measured using the L-Lactate assay kit (Abcam, plc., Cambridge, $\mathrm{UK})$. The serum levels of $\mathrm{CK}, \mathrm{BUN}$, and glucose were determined using an automated analyzer (SPOTCHEM EZ SP-4430, ARKRAY, Inc., Minneapolis, MN, USA). Serum ALT concentrations were determined using the ALT Discrete Pak Kit (Catachem Inc., Bridgeport, CT, USA).

\subsection{Tissue Glycogen Determination}

The glycogen content of the liver and muscle tissues were determined using the Glycogen Colorimetric Assay Kit II (BioVision Inc., Milpitas, CA, USA), according to the manufacturer's protocols. 


\subsection{Tissue GSH Determination}

The Glutathione Assay Kit was purchased from Cayman Chemical Company (Ann Arbor, MI, USA) for the determination of GSH content in the liver and muscle tissues; the assay was performed according to the manufacturer's recommended procedures.

\subsection{Western Blot Analysis}

Proteins were isolated from liver tissue and analyzed as previously described $[25,26]$. In brief, liver tissues (50-100 mg) were homogenized in $1 \mathrm{~mL}$ of RIPA with $1 \%$ protease inhibitor cocktail solution using a Polytron disrupter. The protein samples collected by centrifuge were loaded onto $12.5 \%$ sodium dodecyl sulfate polyacrylamide gel electrophoresis (SDS-PAGE) and transferred to polyvinylidene difluoride (PVDF) membranes (ImmobilonP; Millipore). The PVDF membrane was further blocked using 5\% skim milk in Tris-buffered saline buffer with Tween 20 (TBST) for $1 \mathrm{~h}$ at room temperature, then incubated overnight at $4{ }^{\circ} \mathrm{C}$ with primary antibodies TNF- $\alpha$ (Proteintech Group, Inc, Rosemont, IL, USA) and $\beta$-actin (Cell Signaling Technology, Inc., Beverly, MA, USA). After washing using TBST, the membranes were incubated with horseradish peroxidase-labeled secondary antibodies (Jackson ImmunoResearch Inc., West Grove, PA, USA) for $1 \mathrm{~h}$ at room temperature. The membrane signals were then developed using enhanced chemiluminescence (ECL) (GE Healthcare Bio-Sciences, Pittsburgh, PA, USA) and detected using the Luminescence Image System (Hansor Polymer Technology Corp., Taichung, Taiwan).

\subsection{Statistical Analysis}

All data were expressed as mean \pm SEM. The statistical analyses were conducted using GraphPad Prism software package version 5.0 (GraphPad Software; San Diego, CA, USA). Unpaired two-tailed $t$-test or one-way ANOVA with Tukey's post hoc test were used to calculate statistical difference among the groups, and significance was set at $p<0.05$.

\section{Results and Discussion}

\subsection{Effects of HWET on the Body Weight, Food Intake, and Skeletal Muscle Mass of Mice}

Table 2 summarizes the initial body weight, final body weight, food intake and muscle weight of the forelimbs. Previous studies reported that training programs may reduce body weight if the condition of the participants or animals was abnormal, due to obesity or a metabolic syndrome $[27,28]$. Moreover, some pathological and clinical observations, such as a reduction in body weight or food consumption, could reflect the toxicity of the chemicals or supplements [29]. As there was no significant difference in initial body weight, final body weight, or food intake among the control or HWET treatment groups $(p>0.05)$, the general condition of all mice was assumed to be normal at the beginning of the experiment. Furthermore, continuous supplementation with HWET for 7 days did not show any adverse effects or impact food intake or gains in body weight. In addition, the muscle weight of the forelimbs among the four groups did not differ markedly, which indicated that oral administration of HWET did not affect muscle mass during the experimental period.

Table 2. A summary of body weight, food intake, and skeletal muscle mass.

\begin{tabular}{lcccc}
\hline & Control & HWET-L & HWET-M & HWET-H \\
\hline Initial body weight $(\mathrm{g})$ & $33.5 \pm 0.6$ & $33.5 \pm 0.5$ & $33.6 \pm 0.4$ & $33.5 \pm 0.4$ \\
Final body weight $(\mathrm{g})$ & $34.3 \pm 0.6$ & $35.3 \pm 1.0$ & $35.0 \pm 0.6$ & $34.1 \pm 0.7$ \\
Food intake (g/day) & $5.45 \pm 0.15$ & $5.66 \pm 0.19$ & $5.49 \pm 0.14$ & $5.26 \pm 0.17$ \\
Muscle weight (g) & $0.30 \pm 0.01$ & $0.31 \pm 0.01$ & $0.29 \pm 0.01$ & $0.30 \pm 0.02$ \\
\hline
\end{tabular}

Data are presented as the mean \pm SEM for $\mathrm{n}=10$ per group. Muscle weight of forelimbs was measured $1 \mathrm{~h}$ after swimming endurance test.

\subsection{Effects of HWET on Exercise Performance in Swimming Endurance Test}

As shown in Figure 1, the swimming times of the control, HWET-L, HWET-M, and HWET-H groups were $263.6 \pm 22.3$ s, $351.8 \pm 27.0$ s, $392.4 \pm 32.3$ s, and $451.3 \pm 20.6 \mathrm{~s}$, 
respectively. The administration of HWET significantly enhanced the exercise capacity of the mice in a dose-dependent manner $(p<0.05)$. Compared to the control group, the swimming times of the HWET-L, HWET-M, and HWET-H groups increased 1.3-fold, 1.5-fold, and 1.7-fold, respectively. Previous studies showed that supplementation with branched-chain amino acids (BCAA) and taurine enhanced athletic performance by reducing exercise-induced muscle soreness and damage [30,31]. BCAA provide higher substrate bioavailability to support protein synthesis, alleviating the level of muscle damage associated with strenuous exercise. HWET is rich in protein and possesses a considerable amount of BCAA and taurine (as shown in Table 1), suggesting that this is one of the major factors in improving exercise performance.

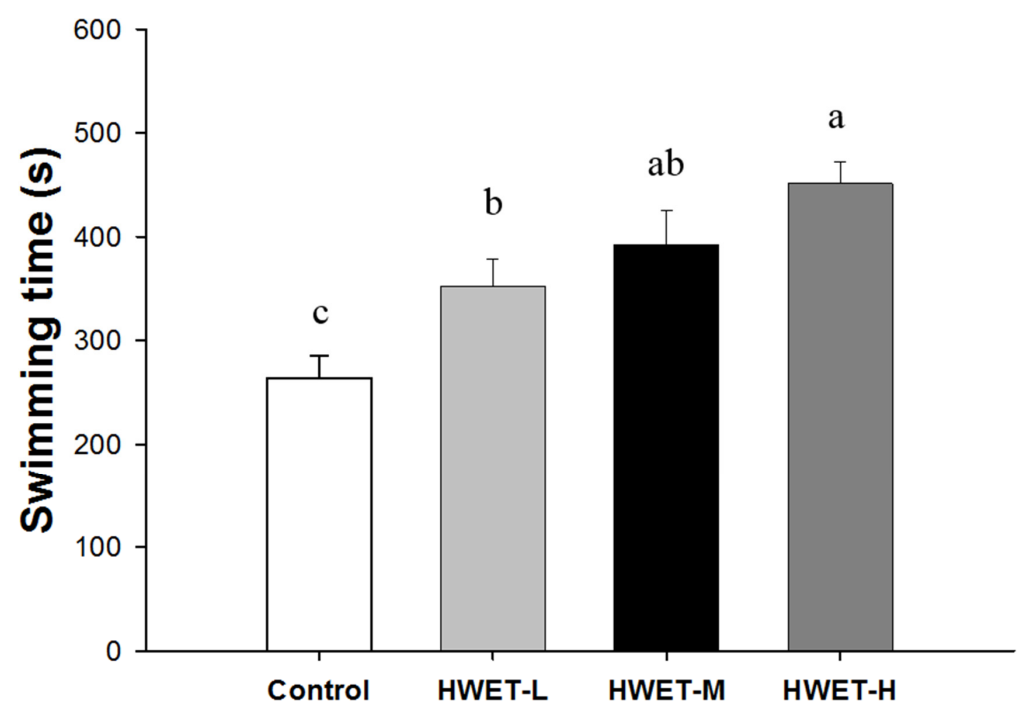

Figure 1. Effects of HWET treatment on swimming time in ICR mice. Mice were treated with vehicle (control), $800 \mathrm{mg} / \mathrm{kg}$ (HWET-L), $1600 \mathrm{mg} / \mathrm{kg}$ (HWET-M), or $4000 \mathrm{mg} / \mathrm{kg}$ (HWET-H) of HWET once per day for 7 days, and conducted the swimming test $1 \mathrm{~h}$ after the last administration. Values are expressed as the mean \pm SEM. Different letters indicate statistical difference, $p<0.05$.

3.3. Effects of HWET on Serum Levels of Lactate, Creatine Kinase (CK), Alanine Aminotransferase $(A L T)$, and Blood Urea Nitrogen (BUN) in Mice

To confirm whether orally administered HWET changes blood biochemical parameters to enhance exercise performance, blood was collected from mice $1 \mathrm{~h}$ after the swimming endurance test and serum samples were prepared to measure lactate, CK, BUN, glucose, and ALT levels. Lactate is the end product of anaerobic metabolism. Glycolysis produces pyruvate, which is converted into lactate under anaerobic conditions. Following high-intensity exercise over a short period, anaerobic glycolysis leads to abundant lactate accumulation in the muscle and liver [32]. Our results showed that the serum lactate concentrations in the HWET-treated groups were lower than that of the control group (Figure 2A). Significant differences can be observed in the HWET-M $(1600 \mathrm{mg} / \mathrm{kg} /$ day $)$ and HWET-H (4000 mg/kg/day) groups compared to the control group $(p<0.05)$. This suggests that HWET could alleviate fatigue by lowering blood lactate levels in mice. CK, also known as creatine phosphokinase (CPK), is found in skeletal muscle, the myocardium, and other organs, but the majority is in skeletal muscle, accounting for $96 \%$ of the total amount. The main function of CK is to help energy synthesis during short-term intense exercise. When the muscle is damaged, the rupture or increased permeability of the cell membrane causes a large amount of CK to be released into the blood. Therefore, the amount of $\mathrm{CK}$ in the blood is commonly used as an indicator to assess muscle damage following exercise [33]. As shown in Figure 2B, significant reductions in serum CK levels in the HWET-L (1319 $\pm 190 \mathrm{IU} / \mathrm{L})$, HWET-M (942 $\pm 115 \mathrm{IU} / \mathrm{L})$, and HWET-H (555 $\pm 58 \mathrm{IU} / \mathrm{L})$ groups were noted compared to the control group $(2052 \pm 315 \mathrm{IU} / \mathrm{L})$, indicating that HWET reduced exercise-induced muscle damage and fatigue. Figure $2 \mathrm{C}$ shows the effects 
of HWET treatment on ALT levels in mice following the endurance test. Compared to the control group, HWET significantly decreased ALT levels by $48 \%, 30 \%$, and $70 \%$ in the HWET-L, HWET-M, and HWET-H groups, respectively. Studies have shown that elevated ALT is associated with fatigue, anorexia, or pruritus, and increases the risk of clinical liver disease [34]. Drugs or supplements that reduce serum ALT levels may potentially prevent liver disease. However, there were no dose-dependent decreases in ALT levels after HWET treatment. In the future, further studies on the protection of HWET on the liver must be performed to examine, for instance, whether HWET can protect mice against carbon tetrachloride-induced liver damage. BUN is the final product from the decomposition of proteins and amino acids in the human body following intense exercise. BUN can reflect protein and amino acid metabolism in the body, which is related to the individual's functional condition and fatigue [35]. However, although HWET treatment slightly decreased BUN levels in mice, the levels did not significantly differ among the groups $(p>0.05)$ (Figure 2D).

(A)

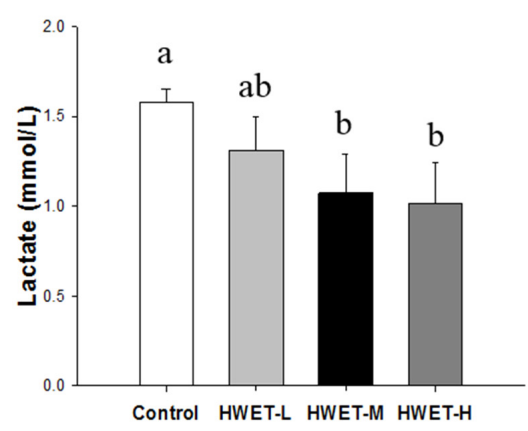

(C)

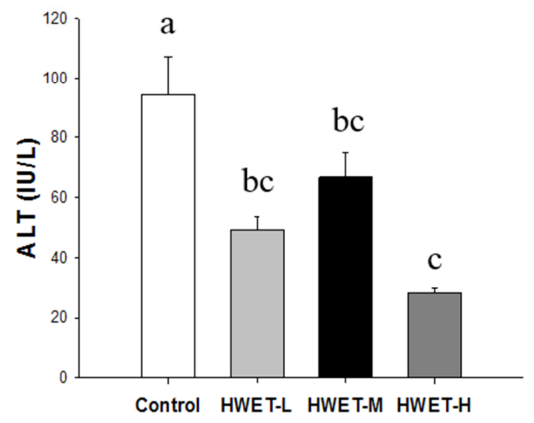

(B)

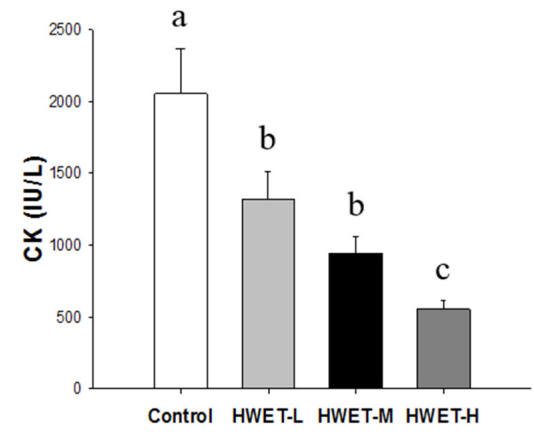

(D)

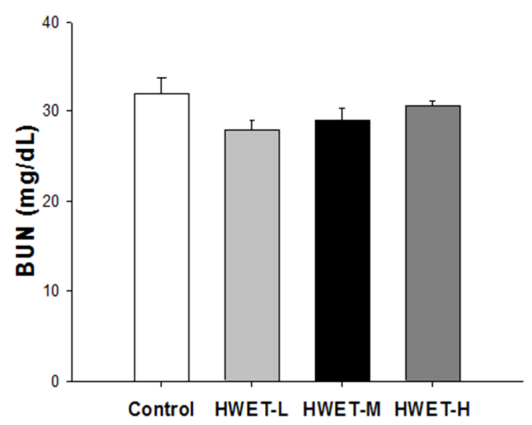

Figure 2. Effects of HWET treatment on serum levels of (A) lactate, $(\mathbf{B})$ creatine kinase $(\mathrm{CK}),(\mathrm{C})$ alanine aminotransferase (ALT), and (D) blood urea nitrogen (BUN) in mice after a swimming endurance test. Values are expressed as the mean \pm SEM. Different letters indicate statistical difference, $p<0.05$.

\subsection{Effects of HWET on Serum Levels of Glucose in Mice}

Glucose is the major source of energy in the body during exercise [36]. Figure 3 shows the serum glucose levels in mice after the endurance test. Serum glucose was significantly higher in the HWET-M $(86.5 \pm 8.8 \mathrm{mg} / \mathrm{dL})$ and HWET-H $(104.4 \pm 5.1 \mathrm{mg} / \mathrm{dL})$ groups compared to the control $(64.9 \pm 5.4 \mathrm{mg} / \mathrm{dL})(p<0.05)$, although there was no statistical difference between HWET-L $(59.9 \pm 8.6 \mathrm{mg} / \mathrm{dL})$ and the control group, indicating that HWET, when administered in a sufficient concentration, increased the serum concentration of glucose to provide sufficient energy to the mice during exercise. 


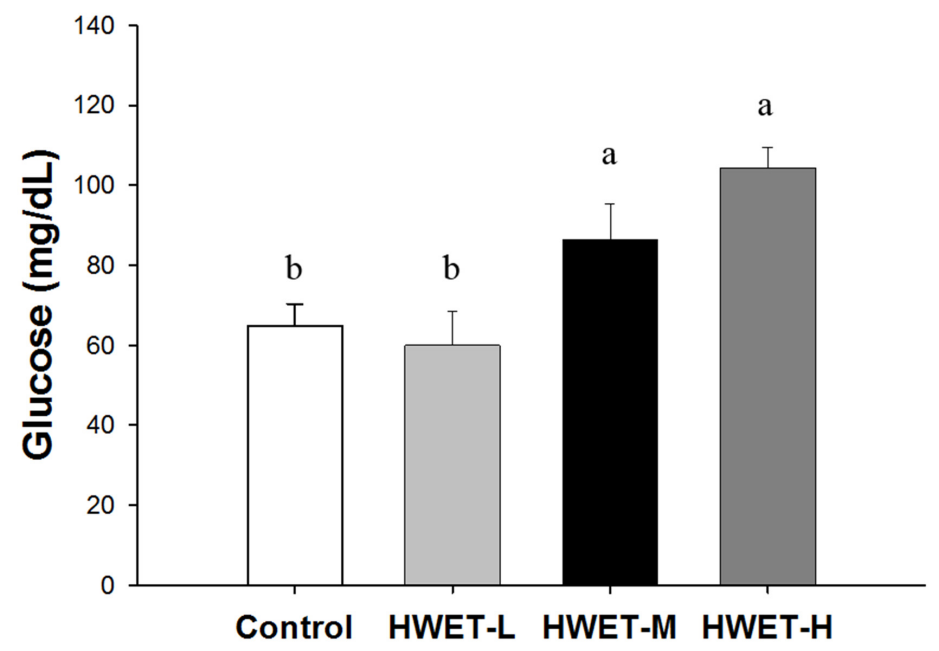

Figure 3. Effects of HWET treatments on serum glucose levels in mice after a swimming endurance test. Values are expressed as the mean \pm SEM. Different letters indicate statistical difference, $p<0.05$.

\subsection{Effects of HWET on Glycogen Levels in Liver and Muscle in Mice}

At the end of the experiment, the liver and forelimb muscle tissues were collected, and glycogen levels were measured. Carbohydrates are a major energy source during endurance exercise, and the most important source of carbohydrates is in the glycogen stores within muscle [37]. Our results showed that oral administration of HWET significantly increased glycogen content in the liver, but only slightly enhanced that of muscle tissue (Figure 4). Chen et al. [38] also indicated that a mixture of fermented tilapia by-products and Monostroma nitidum oligosaccharides significantly increased liver glycogen content and decreased BUN level post-exercise. It has been proposed that the re-synthesis of liver glycogen is the first priority when glucose is available after exercise, followed by the synthesis of muscle glycogen [39].

(A)

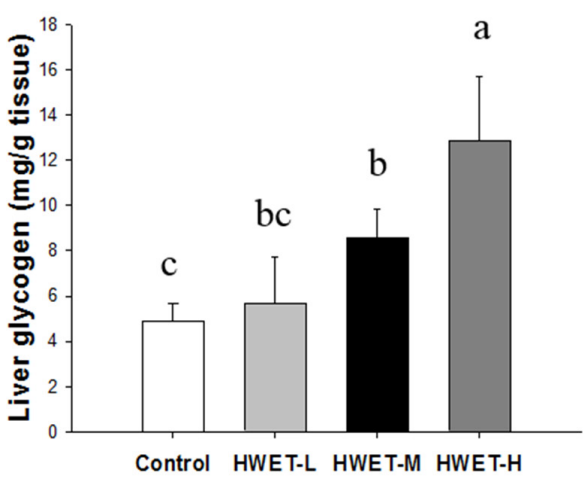

(B)

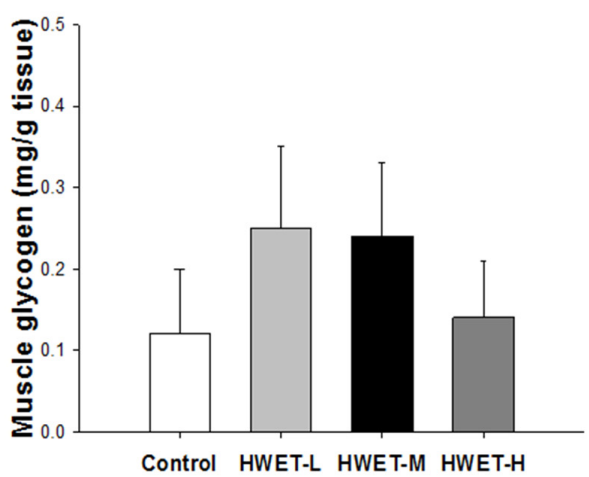

Figure 4. Effects of HWET treatment on glycogen levels in (A) liver and (B) muscle of mice after swimming endurance test. Mice were treated with vehicle (control), $800 \mathrm{mg} / \mathrm{kg}$ (HWET-L), $1600 \mathrm{mg} / \mathrm{kg}$ (HWET-M), or $4000 \mathrm{mg} / \mathrm{kg}$ (HWET-H) of HWET once per day for 7 days; all mice were euthanized and glycogen levels in liver and muscle tissues measured $1 \mathrm{~h}$ after swimming endurance test. Values are expressed as the mean \pm SEM. Different letters indicate statistical difference, $p<0.05$.

\subsection{Effects of HWET on GSH Contents in the Liver and Muscle of Mice}

As shown in Figure 5, GSH levels in the liver and muscle were measured to assess the capacity of the antioxidant defense system in mice against exercise-induced oxidative stress. The results showed that HWET treatment significantly enhanced GSH levels in liver tissue $(p<0.05)$. Furthermore, GSH levels in muscle tissue significantly improved in the HWET-M and HWET-H groups compared to the control $(p<0.05)$. Previous studies reported that protein and BCAA supplementation helps maintain glutathione production [40]. The high 
levels of protein and BCAA in HWET enhanced the ability of the GSH antioxidant defense system in mice to improve muscle strength and provide a continuous source of energy.

(A)

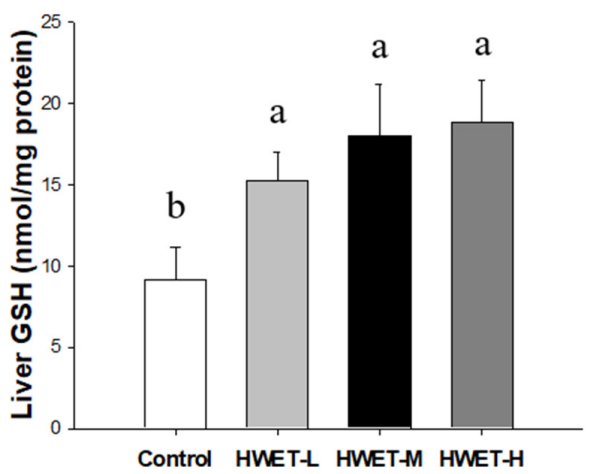

(B)

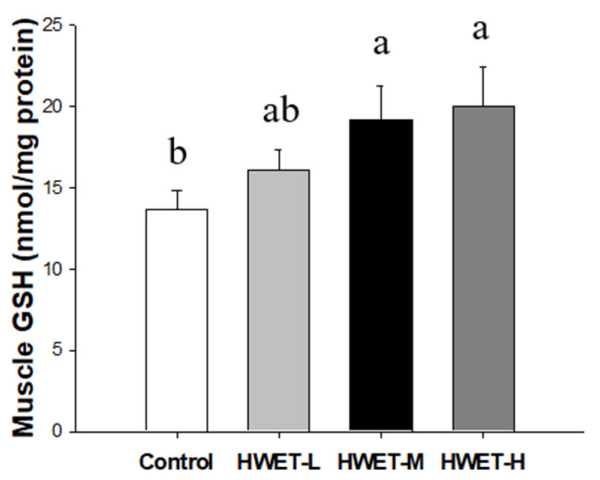

Figure 5. Effects of HWET treatment on GSH content in (A) liver and (B) muscle of mice after swimming endurance test. Mice were treated with vehicle (control), $800 \mathrm{mg} / \mathrm{kg}$ (HWET-L), $1600 \mathrm{mg} / \mathrm{kg}$ (HWET-M), or $4000 \mathrm{mg} / \mathrm{kg}$ (HWET-H) of HWET once per day for 7 days; all mice were euthanized and GSH content in liver and muscle tissues measured $1 \mathrm{~h}$ after swimming endurance test. Values are expressed as the mean \pm SEM. Different letters indicate statistical difference, $p<0.05$.

\subsection{Effects of HWET on TNG- $\alpha$ Expression in Liver of Mice}

Figure 6 shows the expression of TNF- $\alpha$ protein in mice after the swimming endurance test. HWET treatment down-regulated the expression of TNF- $\alpha$ in liver tissue following exercise in a dose-dependent manner. Significantly elevated TNF- $\alpha$ in the body is highly associated with fatigue and is associated with fatigue-induced oxidative parameters [41]. HWET treatment alleviated the oxidative stress induced by fatigue following exercise by suppressing the expression of TNF- $\alpha$ protein, which corresponds to the enhanced GSH levels in the liver.
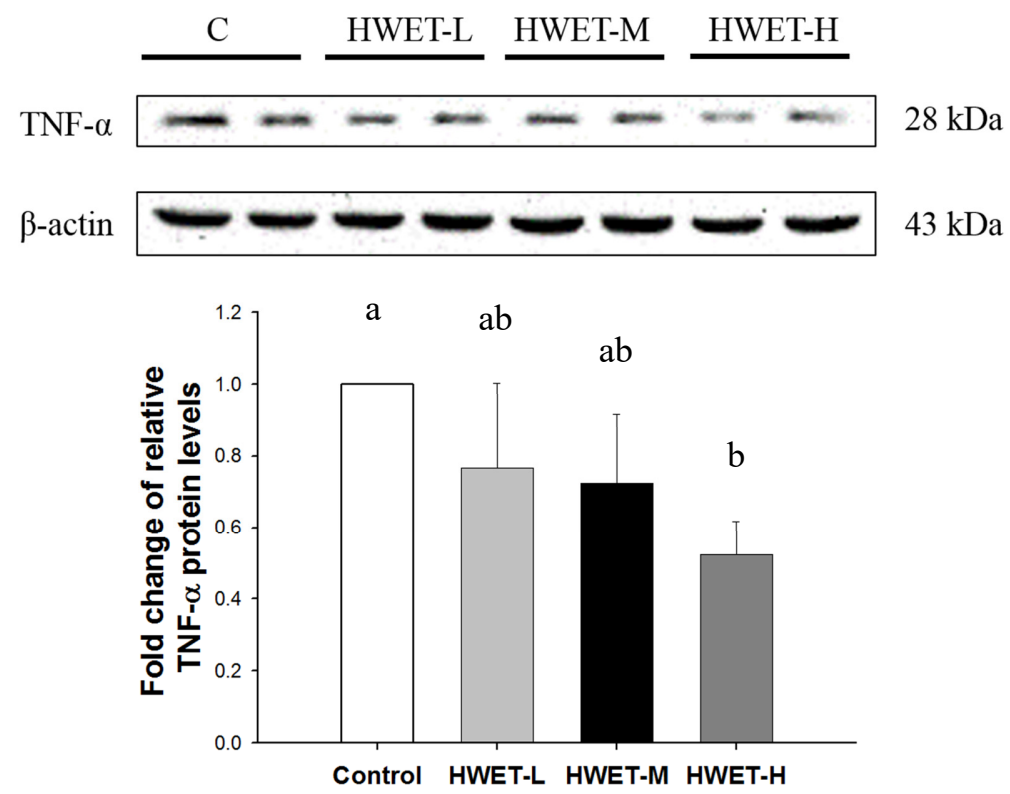

Figure 6. Effects of HWET treatment on TNF- $\alpha$ expression in liver of mice after swimming endurance test. Mice were treated with vehicle (control), $800 \mathrm{mg} / \mathrm{kg}$ (HWET-L), $1600 \mathrm{mg} / \mathrm{kg}$ (HWET-M), or $4000 \mathrm{mg} / \mathrm{kg}$ (HWET-H) of HWET once per day for 7 days; all mice were euthanized and analyzed for TNF- $\alpha$ expression in liver tissue $1 \mathrm{~h}$ after swimming endurance test. Values are expressed as the mean \pm SEM. Different letters indicate statistical difference, $p<0.05$. 


\section{Conclusions}

In summary, our results demonstrated that oral administration of HWET is an effective strategy for enhancing exercise performance in a mouse model. HWET treatment significantly increased the swimming time compared to the control group, reduced serum levels of lactate, $\mathrm{CK}$, and BUN, and increased serum glucose levels and glycogen content in the liver. Moreover, increased GSH content in muscle and liver tissues and suppressed hepatic TNF- $\alpha$ expression, indicative of reduced oxidative stress, were also found in the HWET-supplemented groups. To the best of our knowledge, this study is the first to show that HWET can enhance the exercise capacity of mice in a swimming endurance model. Data obtained from the present study show that HWET could potentially be developed into functional anti-fatigue foods or nutritional supplements; however, the molecular mechanisms of its anti-fatigue activity need further investigation.

Author Contributions: Conceptualization, H.-Y.T. and Y.-K.C.; methodology, J.-F.Y. and F.-N.Y.; software, F.-N.Y. and Y.-H.L.; validation, H.-H.C. and Y.-H.L.; formal analysis, H.-Y.T., J.-F.Y. and Y.-J.Z.; investigation, F.-N.Y. and Y.-J.Z.; resources, Y.-K.C. and C.-I.C.; data curation, H.-Y.T. and J.-L.H.; writing —original draft preparation, H.-Y.T.; writing—review and editing, H.-H.C. and Y.K.C.; visualization, H.-Y.T.; supervision, Y.-K.C.; project administration, H.-Y.T. and Y.-K.C.; funding acquisition, Y.-K.C. All authors have read and agreed to the published version of the manuscript.

Funding: This work was supported, in part, by the Ministry of Science and Technology, Taiwan, under grants MOST 105-2311-B-020-004 and MOST 108-2320-B-020-002.

Institutional Review Board Statement: The animal study was conducted according to the guidelines of the Taiwan Government Guide for the Care and Use of Laboratory Animals, and approved by the Institutional Animal Care and Use Committee of National Pingtung University of Science and Technology (protocol NPUST-110-038).

Informed Consent Statement: Not applicable.

Data Availability Statement: Not applicable.

Acknowledgments: The authors would like to thank Chien-Hsing Chiang and Chih-Chiang Tsai of the Li Chuan Aquafarm Co., Ltd. (Hualien, Taiwan) for providing the tilapia extract used in this study.

Conflicts of Interest: The authors declare no conflict of interest.

\section{References}

1. Nam, S.Y.; Kim, H.M.; Jeong, H.J. Anti-fatigue effect by active dipeptides of fermented porcine placenta through inhibiting the inflammatory and oxidative reactions. Biomed. Pharmacother. 2016, 84, 51-59. [CrossRef] [PubMed]

2. Kim, K.M.; Yu, K.W.; Kang, D.H.; Suh, H.J. Anti-stress and anti-fatigue effect of fermented rice bran. Phytother. Res. 2002, 16, 700-702. [CrossRef] [PubMed]

3. Nakagawa, S.; Takeuchi, H.; Taki, Y.; Nouchi, R.; Kotozaki, Y.; Shinada, T.; Maruyama, T.; Sekiguchi, A.; Iizuka, K.; Yokoyama, R.; et al. Basal ganglia correlates of fatigue in young adults. Sci. Rep. 2016, 6, 21386. [CrossRef] [PubMed]

4. Zhao, H.P.; Zhang, Y.; Liu, Z.; Chen, J.Y.; Zhang, S.Y.; Yang, X.D.; Zhou, H.L. Acute toxicity and anti-fatigue activity of polysaccharide-rich extract from corn silk. Biomed. Pharmacother. 2017, 90, 686-693. [CrossRef] [PubMed]

5. Zajac, A.; Chalimoniuk, M.; Maszczyk, A.; Golas, A.; Lngfort, J. Central and peripheral fatigue during resistance exercise-A critical review. J. Hum. Kinet. 2015, 49, 159-169. [CrossRef]

6. Parry-Billings, M.; Blomstrand, E.; McAndrew, N.; Newsholme, E.A. A communicational link between skeletal muscle, brain, and cells of the immune system. Int. J. Sports Med. 1990, 11 (Suppl. 2), S122-S128. [CrossRef]

7. Newsholme, E.A.; Blomstrand, E. Branched-chain amino acids and central fatigue. J. Nutr. 2006, 136 (Suppl. 1), 274S-276S. [CrossRef]

8. You, L.; Zhao, M.; Regenstein, J.M.; Ren, J. In vitro antioxidant activity and in vivo anti-fatigue effect of loach (Misgurnus anguillicaudatus) peptides prepared by papain digestion. Food Chem. 2011, 124, 188-194. [CrossRef]

9. Marquez, R.; Santangelo, G.; Sastre, J.; Goldschmidt, P.; Luyckx, J.; Pallardo, F.V.; Vina, J. Cyanoside chloride and chromocarbe diethylamine are more effective than vitamin C against exercise-induced oxidative stress. Pharmacol. Toxicol. 2001, 89, 255-258. [CrossRef]

10. Lu, Y.; Lin, Y.; Huang, X.; Wu, S.; Wei, J.; Yang, C. Oxaliplatin aggravates hepatic oxidative stress, inflammation and fibrosis in a nonalcoholic fatty liver disease mouse model. Int. J. Mol. Med. 2019, 43, 2398-2408. 
11. Mytilineou, C.; Kramer, B.C.; Yabut, J.A. Glutathione depletion and oxidative stress. Parkinsonism Relat. Disord. 2002, 8, 385-387. [CrossRef]

12. Uehata, T. Karoshi, death by overwork. Nihon Rinsho 2005, 63, 1249-1253.

13. Herrlinger, K.A.; Chirouzes, D.M.; Ceddia, M.A. Supplementation with a polyphenolic blend improves post-exercise strength recovery and muscle soreness. Food Nutr. Res. 2015, 59, 30034. [CrossRef]

14. Xianchu, L.; Ming, L.; Xiangbin, L.; Lan, Z. Grape seed proanthocyanidin extract supplementation affects exhaustive exerciseinduced fatigue in mice. Food Nutr. Res. 2018, 62, 1421. [CrossRef] [PubMed]

15. Kan, N.W.; Ho, C.S.; Chiu, Y.S.; Huang, W.C.; Chen, P.Y.; Tung, Y.T.; Huang, C.C. Effects of resveratrol supplementation and exercise training on exercise performance in middle-aged mice. Molecules 2016, 21, 661. [CrossRef] [PubMed]

16. Huang, C.C.; Hsu, M.C.; Huang, W.C.; Yang, H.R.; Hou, C.C. Triterpenoid-rich extract from Antrodia camphorata improves physical fatigue and exercise performance in mice. Evid. Based Complement. Alternat. Med. 2012, 2012, 364741. [CrossRef]

17. Xu, M.; Liang, R.; Li, Y.; Wang, J. Anti-fatigue effects of dietary nucleotides in mice. Food Nutr. Res. 2017, 61, 1334485. [CrossRef]

18. Liu, R.; Wu, L.; Du, Q.; Ren, J.W.; Chen, Q.H.; Li, D.; Mao, R.X.; Liu, X.R.; Li, Y. Small molecule oligopeptides isolated from walnut (Juglans regia L.) and their anti-fatigue effects in mice. Molecules 2018, 24, 45. [CrossRef]

19. Ni, W.; Gao, T.; Wang, H.; Du, Y.; Li, J.; Li, C.; Wei, L.; Bi, H. Anti-fatigue activity of polysaccharides from the fruits of four Tibetan plateau indigenous medicinal plants. J. Ethnopharmacol. 2013, 150, 529-535. [CrossRef]

20. Coqueiro, A.Y.; Rogero, M.M.; Tirapegui, J. Glutamine as an anti-fatigue amino acid in sports nutrition. Nutrients 2019, 11, 863. [CrossRef]

21. Ren, J.; Zhao, M.; Wang, H.; Cui, C.; You, L. Effects of supplementation with grass carp protein versus peptide on swimming endurance in mice. Nutrition 2011, 27, 789-795. [CrossRef]

22. Lee, G.H.; Harwanto, D.; Park, S.M.; Choi, J.S.; Kim, M.R.; Hong, Y.K. Hot water extract of leather carp (Cyprinus carpio nudus) improves exercise performance in mice. Prev. Nutr. Food Sci. 2015, 20, 246-252. [CrossRef] [PubMed]

23. McAndrew, B.J.; Penman, D.J.; Bekaert, M.; Wehner, S. Tilapia genomic studies. In Genomics in Aquaculture; MacKenzie, S., Jentoft, S., Eds.; Academic Press: San Diego, CA, USA, 2016; pp. 105-129.

24. Lai, C.F.; Huang, L.C. A bibliography of Tilapia (family cichlidae) in Taiwan. Aquaculture 1981, 22, 389-394. [CrossRef]

25. Liu, B.; Zhang, J.; Sun, P.; Yi, R.; Han, X.; Zhao, X. Raw Bowl Tea (Tuocha) polyphenol prevention of nonalcoholic fatty liver disease by regulating intestinal function in mice. Biomolecules 2019, 9, 435. [CrossRef]

26. Chen, Y.K.; Wang, H.C.; Ho, C.T.; Chen, H.Y.; Li, S.; Chan, H.L.; Chung, T.W.; Tan, K.T.; Li, Y.R.; Lin, C.C. 5-demethylnobiletin promotes the formation of polymerized tubulin, leads to G2/M phase arrest and induces autophagy via JNK activation in human lung cancer cells. J. Nutr. Biochem. 2015, 26, 484-504. [CrossRef] [PubMed]

27. Willis, L.H.; Slentz, C.A.; Bateman, L.A.; Shields, A.T.; Piner, L.W.; Bales, C.W.; Houmard, J.A.; Kraus, W.E. Effects of aerobic and/or resistance training on body mass and fat mass in overweight or obese adults. J. Appl. Physiol. 2012, 113, 1831-1837. [CrossRef] [PubMed]

28. Hafstad, A.D.; Lund, J.; Hadler-Olsen, E.; Hoper, A.C.; Larsen, T.S.; Aasum, E. High- and moderate-intensity training normalizes ventricular function and mechanoenergetics in mice with diet-induced obesity. Diabetes 2013, 62, 2287-2294. [CrossRef] [PubMed]

29. Lent, E.M. Chapter 6-Wildlife toxicity assessment for 2,4-dinitrotoluene and 2,6-dinitrotoluene. In Wildlife Toxicity Assessments for Chemicals of Military Concern; Williams, M.A., Reddy, G., Quinn, M.J., Johnson, M.S., Eds.; Elsevier: Amsterdam, The Netherlands, 2015; pp. 107-146.

30. Howatson, G.; Hoad, M.; Goodall, S.; Tallent, J.; Bell, P.G.; French, D.N. Exercise-induced muscle damage is reduced in resistancetrained males by branched chain amino acids: A randomized, double-blind, placebo controlled study. J. Int. Soc. Sports Nutr. 2012, 9, 20. [CrossRef]

31. Ra, S.G.; Miyazaki, T.; Ishikura, K.; Nagayama, H.; Komine, S.; Nakata, Y.; Maeda, S.; Matsuzaki, Y.; Ohmori, H. Combined effect of branched-chain amino acids and taurine supplementation on delayed onset muscle soreness and muscle damage in high-intensity eccentric exercise. J. Int. Soc. Sports Nutr. 2013, 10, 51. [CrossRef]

32. Brooks, G.A. Intra- and extra-cellular lactate shuttles. Med. Sci. Sports Exerc. 2000, 32, 790-799. [CrossRef]

33. Mougios, V. Reference intervals for serum creatine kinase in athletes. Br. J. Sports Med. 2007, 41, 674-678. [CrossRef]

34. Kim, W.R.; Flamm, S.L.; Di Bisceglie, A.M.; Bodenheimer, H.C. Public Policy Committee of the American Association for the Study of Liver D. Serum activity of alanine aminotsransferase (ALT) as an indicator of health and disease. Hepatology 2008, 47, 1363-1370. [CrossRef] [PubMed]

35. Maddali, S.; Rodeo, S.A.; Barnes, R.; Warren, R.F.; Murrell, G.A. Postexercise increase in nitric oxide in football players with muscle cramps. Am. J. Sports Med. 1998, 26, 820-824. [CrossRef] [PubMed]

36. Geng, P.; Siu, K.C.; Wang, Z.; Wu, J.Y. Antifatigue functions and mechanisms of edible and medicinal mushrooms. Biomed. Res. Int. 2017, 2017, 9648496. [CrossRef] [PubMed]

37. Ivy, J.L. Muscle glycogen synthesis before and after exercise. Sports Med. 1991, 11, 6-19. [CrossRef] [PubMed]

38. Chen, Y.J.; Kuo, C.Y.; Kong, Z.L.; Lai, C.Y.; Chen, G.W.; Yang, A.J.; Lin, L.H.; Wang, M.F. Anti-fatigue effect of a dietary supplement from the fermented by-products of Taiwan tilapia aquatic waste and Monostroma nitidum oligosaccharide complex. Nutrients 2021, 13, 1688. [CrossRef] [PubMed]

39. Chakravarthy, M.V.; Booth, F.W. Eating, exercise, and "thrifty" genotypes: Connecting the dots toward an evolutionary understanding of modern chronic diseases. J. Appl. Physiol. 2004, 96, 3-10. [CrossRef] 
40. Holecek, M. Branched-chain amino acids in health and disease: Metabolism, alterations in blood plasma, and as supplements. Nutr. Metab. 2018, 15, 33. [CrossRef]

41. Lee, J.S.; Kim, H.G.; Lee, D.S.; Son, C.G. Oxidative stress is a convincing contributor to idiopathic chronic fatigue. Sci. Rep. 2018, 8, 12890. [CrossRef] 